\title{
High Power High Speed PM-Assisted SynRel Machines with Ferrite and Rare Earth Magnets for Future Electric Commercial Vehicles
}

\author{
R. M. Ram Kumar ${ }^{\dagger}$, Tianjie Zou $^{\dagger}$,Antonino La Rocca ${ }^{\dagger}$ Gaurang Vakil ${ }^{\dagger \ddagger}$, David Gerada ${ }^{\dagger \ddagger}$, Adam Walker ${ }^{\dagger}$, \\ Chris Gerada $^{\dagger \ddagger}$, Krzysztof Paciura ${ }^{\S}$, Alastair McQueen ${ }^{\S}$ and B. G. Fernandes $₫$ \\ $\dagger$ Power Electronics, Machines and Control Group, University of Nottingham, Nottingham NG7 2RD, U.K, \\ $\ddagger$ Ningbo 315000, China, ${ }^{\S}$ Cummins Corporate R\&T, Peterborough, PE2 6FZ, U.K, \\ I Department of Electrical Engineering, Indian Institute of Technology - Bombay, Powai, Mumbai - 400076, India \\ Email: ramkumar.ramanathan@nottingham.ac.uk, gaurang.vakil@nottingham.ac.uk
}

\begin{abstract}
High power density and high torque density are the fundamental requirements for electric machines used in traction application. The former is obtained by potentially increasing the speed of the machine while the latter by using high energy density rare earth magnets. Ferrite magnets are explored as a viable alternative to rare earth magnets which are relatively expensive and geographically concentrated. The paper is intended to bring out the current trend of electric machines used in electric vehicles (EVs) with due focus on permanent magnet assisted synchronous reluctance (PM-SynRel) machine. High power and high speed PM-SynRel machine with rare earth and ferrite magnets are designed and compared based on the requirements for a future electric commercial vehicles. The ratio of stack length, mass of magnet, total mass and inertia of rare earth machine in comparison to ferrite PM-SynRel is found to be $0.72,0.42,0.72$ and 0.32 , respectively. Based on these, the rare earth based machine is found to have high power density, torque density and also utilizes lesser volume of magnets but PM-SynRel with ferrite is getting closer.
\end{abstract}

Index Terms-High power, high speed, PM-Assisted SynRel, Ferrite, NdFeB

\section{INTRODUCTION}

Tailpipe regulation has a formidable impact on the power train strategy. EVs can meet the required pollutant emission and $\mathrm{CO}_{2}$ standards [1]. EVs are extensively investigated as an alternate for IC Engines by major automobile manufactures to meet the government regulations and customer demands [2]. Also the major technological developments in the field of electric machines and power electronics has propelled the growth of EVs. However, the major obstruction is the relatively poor energy density of batteries compared to gasoline [3] which significantly increases the on-board weight. Therefore, high power density is demanded from other components of the EVs like the motor and power electronics to balance the on-board weight.

Electric machine with high power density and torque density can markedly reduce the space occupied in EVs. High power density is achieved by increasing the speed of the machine while high torque density is realized by incorporating high energy density rare earth magnets like $\mathrm{NdFeB}$ and SmCo [4].
The mechanical stress becomes a critical factor which limits the motor design with the improvement in speed. Despite their high field weakening capability [5], Interior Permanent Magnet (IPM) and PM-SynRel machines have been avoided for high speed application in the past due to the highly sensitive nature of the iron ribs. However, materials with high mechanical yield strength are currently available in the market [6]. This has led to revival of IPM and SynRel machines for high power high speed applications. PM-Assisted SynRel machines are relatively unexplored for traction application compared to IPM machines.

The volatility in the availability and price of rare earth magnet has been encountered in the past due to the geographical concentration of its resources [7]. This had enabled extensive research in the replacement of rare earth magnets with low energy density and relatively cheap ferrite magnets. The contribution of ferrite magnet towards power factor improvement is less compared to $\mathrm{NdFeB}$ magnets. Therefore, the ferrite magnets increases the stress on the power electronic converter in addition to the increase in the mass of the machine. Aforementioned reasons justify the need for design and comparison of PM-Assisted SynRel machine with ferrite and rare earth magnets for high power high speed traction applications. In addition, the amount of magnet in PM-SynRel machine is less compared to the IPM machine [8].

Automobiles were equipped with low power electric motors in the form of automatic steering, starter, sunroof, windshield, etc even prior to the advent of EVs [4]. The use of motors in automobiles is not relatively new. However, EVs demanded the replacement of IC engines with a high power electric motor which has led to a major change in drive train architecture. The current trend of traction machines is discussed in the subsequent section. The importance of PM-SynRel machine as a viable alternative is briefly discussed in the following section. The design and comparison of high power and high speed PM-SynRel machine with ferrite and rare earth magnets is performed and thoroughly analysed. The major impact of the type of magnet used in PM-Assisted SynRel machine is 
TABLE I

CURRENTLY USED MOTOR IN EVS [9]

\begin{tabular}{cc}
\hline \hline Motor Type & Vehicles Used In \\
\hline IM & Tesla Model S, Tesla Model X, Toyota RAV4, GM EV1 \\
BLDC & Toyota Prius (2005) \\
SRM & Chloride Lucas \\
PMSM & Toyota Prius, Nissan Leaf, Soul EV \\
Axial Flux & Renovo Coupe \\
PM-SynRel & BMW i3 \\
\hline \hline
\end{tabular}

TABLE II

CONSTANT POWER RANGE OF VARIOUS MACHINES EMPLOYED IN EVS [10]

\begin{tabular}{cccc}
\hline \hline & $\begin{array}{c}\text { Rated } \\
\text { Speed (rpm) }\end{array}$ & $\begin{array}{c}\text { Maximum } \\
\text { Speed (rpm) }\end{array}$ & $\begin{array}{c}\text { Constant } \\
\text { Power Range }\end{array}$ \\
\hline Induction & 1750 & 8750 & $1: 5$ \\
BLDC & 4000 & 9000 & $1: 2.25$ \\
SRM & 4000 & 20000 & $1: 3$ \\
& & & (Rest in Natural Mode) \\
\hline \hline
\end{tabular}

outlined in the final section.

\section{CURRent TREnds in traction machines}

The use of brushed DC motor, PM brushless DC motor (BLDC), permanent magnet synchronous motor (PMSM), induction motor (IM), switched reluctance motor (SRM) and PM-SynRel machines have been reported for traction application [9]. The type of motor employed in few currently available EVs are listed in Table I. Traction motor should have high torque density and power density. Furthermore, they should also be able to deliver constant power over a wide speed range. The constant power range of various electric machines which were used in EVs are listed in Table II [10]. The significant field weakening capability of IM and SRM is negated by the poor power factor and efficiency of these machines. The efficiency and power factor are the major contributing factors for the range of the EVs.

The future demands on range and efficiency are very difficult to accomplish with electrical machines without PMs like IM, SRM and SynRel. This had led to extensive research on IPM machines in the recent past. The IPM machine with V shaped rotor configuration is widely used in traction application. The 2008 LS 600h, Hybrid Camry, 2004 Prius and 2010 Prius have incorporated an IPM machine. The parameters of these machines are listed in Table III [11]. The maximum rotational speed of Prius 2010 is more than twice of Prius 2004. This is accomplished with nearly the same rotor outer diameter leading to a significant increase in peripheral speed. The power density and specific power is also found to have an increasing trend.

Rare earth $\mathrm{NdFeB} \mathrm{PMs} \mathrm{are} \mathrm{used} \mathrm{in} \mathrm{all} \mathrm{the} \mathrm{IPM} \mathrm{machines}$ listed in Table. III. Currently, IPM machines with ferrite magnets are not reported for commercially available EVs. The IPM machine with spoke configuration is required to overcome the poor performance of ferrite magnets by enabling flux concentration [12]. However, in case of a high
TABLE III

RATINGS OF IPM MACHINES USED IN EVS AND HEVS

\begin{tabular}{|c|c|c|c|c|}
\hline Parameter & $\begin{array}{c}\text { Prius } \\
2004\end{array}$ & $\begin{array}{c}\text { Camry } \\
2007\end{array}$ & $\begin{array}{c}\text { LS 600h } \\
2008\end{array}$ & $\begin{array}{c}\text { Prius } \\
2010\end{array}$ \\
\hline Machine & IPM with & IPM with & IPM with & IPM with \\
\hline Type & $\mathrm{V}$ design & $\mathrm{V}$ design & $\begin{array}{c}\text { triangular } \\
\text { design }\end{array}$ & $\begin{array}{c}\mathrm{V} \text { design } \\
\mathrm{V}\end{array}$ \\
\hline $\begin{array}{l}\text { Peak Power } \\
(\mathrm{kW})\end{array}$ & 50 & 70 & 110 & 60 \\
\hline $\begin{array}{l}\text { Peak Torque } \\
\text { (Nm) }\end{array}$ & 400 & 270 & 300 & 205 \\
\hline $\begin{array}{l}\text { Rotor OD } \\
\quad(\mathrm{mm})\end{array}$ & 160.5 & 160.5 & 129.1 & 160.4 \\
\hline $\begin{array}{l}\text { Rotational } \\
\text { Speed (rpm) }\end{array}$ & 6000 & 14000 & 10230 & 13500 \\
\hline $\begin{array}{l}\text { Peripheral } \\
\text { Speed }(\mathrm{m} / \mathrm{s})\end{array}$ & 50.42 & 117.65 & 69 & 113.38 \\
\hline $\begin{array}{c}\text { Peak Power } \\
\text { Density }(\mathrm{kW} / \mathrm{L})\end{array}$ & 3.25 & 4.73 & 6.59 & 4.8 \\
\hline $\begin{array}{c}\text { Peak Specific } \\
\text { Power }(\mathrm{kW} / \mathrm{kg})\end{array}$ & 1.11 & 1.68 & 2.46 & 1.6 \\
\hline Magnet Type & $\mathrm{NdFeB}$ & $\mathrm{NdFeB}$ & $\mathrm{NdFeB}$ & $\mathrm{NdFeB}$ \\
\hline $\begin{array}{l}\text { Magnet Mass } \\
(\mathrm{kg})\end{array}$ & 1.232 & 0.928 & 1.349 & 0.768 \\
\hline
\end{tabular}

speed application the mechanical performance of a spoke type machine is very difficult to achieve compared to other IPM topologies. This has placed a significant restriction on the use of ferrite magnets in IPM machines used for traction applications. In addition to this the operating temperature of the traction machines are more than $100^{\circ} \mathrm{C}$. The change in remanence with temperature for $\mathrm{NdFeB}$ magnets is about 0.09 to $0.11(\% \mathrm{~K})$ while that for ferrite magnets is $0.19(\% \mathrm{~K})$. The presence of high temperature significantly weakens the flux density of low energy density ferrite magnets compared to rare earth magnets. This highly effects the high speed performance of the machine. Another major disadvantage of ferrite magnets for high power application is its relatively poor demagnetization withstand capability compared to rare earth magnets. Several topologies with ferrite magnets have been reported in literature to reduce the risk of demagnetization. Finally, the quantity of ferrite magnets required to achieve the same power will be much higher compared to the rare earth magnets. However, since the density of ferrite is lower compared to rare earth magnets, the increase in weight does not significantly effect the mechanical stress.

The on board power demand from the electrical machine used in EVs is currently in the order of few hundred kWs. The trend in power demand is also found to increase with the EVs being extended for heavy duty trucks. This is much higher compared to the machines listed in Table III. Electrical machines with peripheral speed in the range of $150 \mathrm{~m} / \mathrm{s}$ to $250 \mathrm{~m} / \mathrm{s}$ belong to the category of high speed machines [6]. The application of high speed machines have been reported for turbochargers [13], microturbines, air compressors, turbomolecular pumps, etc. However, the use of high speed machines is relatively absent in traction application. All the machines listed in Table III have a peripheral speed less than $150 \mathrm{~m} / \mathrm{s}$. The demand for high power and at high power density 
TABLE IV

TARGET SPECIFICATIONS OF THE MACHINE

\begin{tabular}{cc}
\hline \hline Rated Speed (rpm) & 4500 \\
Rated Torque (Nm) & 400 \\
Maximum Speed (rpm) & 15000 \\
Torque at maximum speed (Nm) & 135 \\
\hline \hline
\end{tabular}

supports the development of high power high speed machines for traction application.

\section{NEED FOR DEVELOPMENT OF HIGH POWER HIGH SPEED PM-SYNREL}

The reduction in the quantity of rare earth magnets used in traction motors is of prime necessity to ensure regular supply and safeguard the automotive manufactures from the volatility in its price [1]. This can be achieved by either using machines with no magnets like IM, SRM or using machine which has a significant fraction of its torque obtained from reluctance like PM-SynRel. Another possible solution which is potentially explored is the use of ferrite magnets to replace rare earth magnets.

PM-SynRel can be effectively designed either with ferrite magnets or with reduced quantity of rare earth magnets. The comparison of various machine type for traction application is given in [14]. The machine topologies are compared based on constant power speed range, torque per stator current, efficiency over complete operating range and weight. PMSM has a very low constant power speed range. This can be improved only by highly over rating the inverter which is a disadvantage for EVs. Inspite of being rugged the IM is heavy because of its poor power density. IPM motor is a notable competitor for PM-SynRel machine. The technology of IPM is also relatively matured compared to PM-SynRel machine. However, PM-SynRel is found to perform good in all the aforementioned aspects. PM-SynRel machines with rare earth magnets are used in BMW i3 and i8. Chevrolet Volt is equipped with a PM-SynRel machine topology using ferrite magnets [15]. The major share of reluctance torque in these machines enables the motor to produce significant torque in the high speed range.

There are a few significant challenges with the design of SynRel machines. The major problem is the notable torque ripple produced by these machines. However, this can be reduce by proper positioning of the flux barrier ends and the shape of the flux barriers. The design of high power high speed PM-SynRel results in contrasting requirements. The thickness of the iron ribs has to be minimized in order to ensure superior electromagnetic performance. In contrast, the flux barrier thickness need to be increased to handle the stress induced by the centrifugal force at high speed. Identifying the optimal value of iron ribs considering both electromagnetic and mechanical performance is a challenge. Aforementioned reasons justify the need for combined electromagnetic and mechanical design of high power high speed PM-SynRel machine.
TABLE V

PARAMETERS OF THE DESIGNED MACHINE

\begin{tabular}{ccc}
\hline \hline Parameter & NdFeB rotor & Ferrite rotor \\
\hline Poles & 8 & 12 \\
Stator OD $(\mathrm{mm})$ & 288 & 290 \\
Rotor OD $(\mathrm{mm})$ & 190 & 222 \\
Stack length $(\mathrm{mm})$ & 160 & 220 \\
Current density $\left(\mathrm{A} / \mathrm{mm}^{2}\right)$ & 12.9 & 13.1 \\
\hline \hline
\end{tabular}

\section{MACHINE RATING AND DESIGN}

The rated and the high speed torque requirements of the machine are listed in Table IV. The constant power range of this machine is required to be $1: 3$. The high speed machinery are compared based on the concept of $\mathrm{r} / \mathrm{min} \sqrt{\mathrm{kW}}$ [6]. The value of $\mathrm{r} / \mathrm{min} \sqrt{\mathrm{kW}}$ of the machine listed in Table IV is found to be $1.65 \times 10^{5}$. The dynamic problems like stress, critical speed, peripheral speed, etc are expected to be moderate for this machine. In addition, based on the IPM machines reported in literature the development of this machine is possible due to the availability of high strength steel.

Two PM-SynRel machines, one using NdFeB magnets while the other with ferrite magnets are designed and optimised based on the specifications mentioned in Table IV. Genetic algorithm based design optimisation with same degree of freedom, constraints and objective is used to generate the final designs. 10JNEX900, 35HXT780T, N38UH and FB13B are used for the stator lamination, rotor lamination, rare earth and ferrite magnets respectively. The number of poles of high power high speed PM-SynRel should be high to ensure reduction in the volume of iron material. This results in high fundamental frequency of operation at high speed which significantly increases the hysteresis and eddy current loss. Since the fundamental frequency of operation of these machines are quiet high, 10JNEX900 is selected to ensure reduced iron loss in the stator.

The important dimensions of both rotors are shown in Table V. The current density is maintained nearly the same in both designs as the thermal design can be standardized for benchmark comparison. The peripheral speed of $\mathrm{NdFeB}$ rotor is $150 \mathrm{~m} / \mathrm{s}$ while that of ferrite rotor is $175 \mathrm{~m} / \mathrm{s}$. These are quite high for the motors to be considered in the category of high speed machines. The stress induced in the rotor will be significantly high due to the high centrifugal force. Hence, high strength 35HXT780T lamination is chosen for the rotor.

The operating temperature of the machine is established as $100{ }^{\circ} \mathrm{C}$. Hence the magnets are selected to ensure sufficient flux density at such high temperature. The number of poles in $\mathrm{NdFeB}$ and ferrite machines are selected based on the outer dimensions of the rotor. The stack length of ferrite rotor is 60 $\mathrm{mm}$ higher compared to the $\mathrm{NdFeB}$ rotor.

\section{Simulation Results}

The electromagnetic and mechanical FEA analysis are performed with JMAG and ANSYS mechanical package to validate the design. The rotor structure of both machines are 


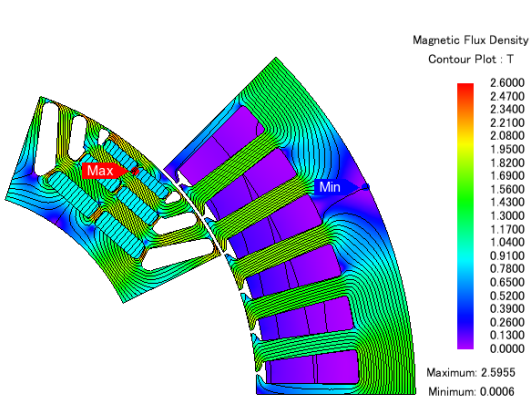

(a)

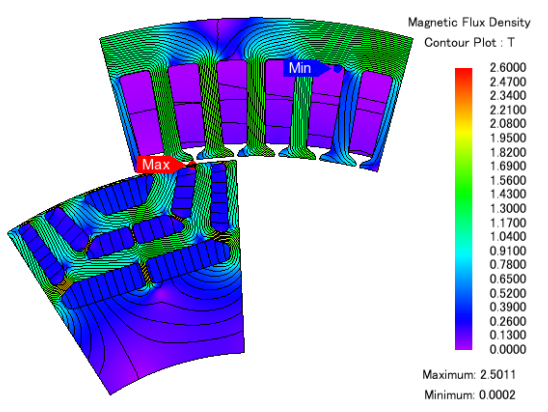

(d)

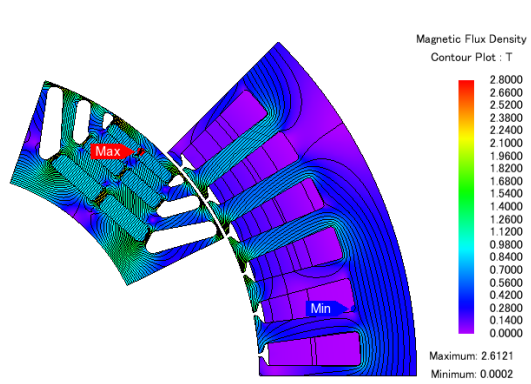

(b)

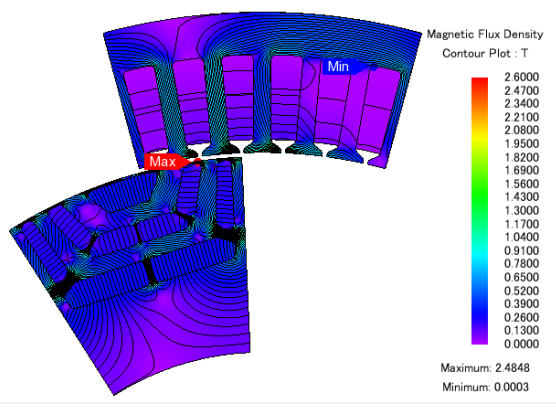

(e)

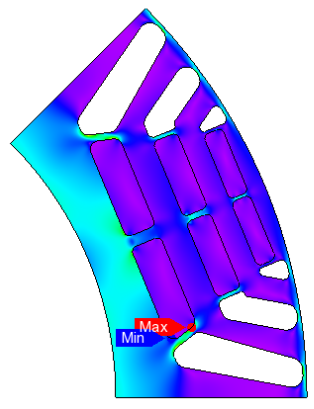

Mises Stress
Contour Plot : MPa

850.0
789.3
7280

789.3

728.6
667.9

667.9
607.1
5464

546.4
485.7

425.0

-5.3
303.6

242.9

242.1
182.1

0.7
0

(c)
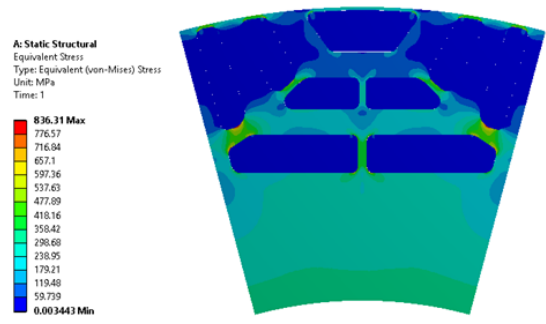

(f)

Fig. 1. Simulation results showing (a) flux density at rated speed of NdFeB machine (b) flux density at maximum speed of NdFeB machine (c) Von Mises stress of NdFeB machine (d) flux density at rated speed of ferrite machine (e) flux density at maximum speed of ferrite machine (f) Von Mises stress of ferrite machine

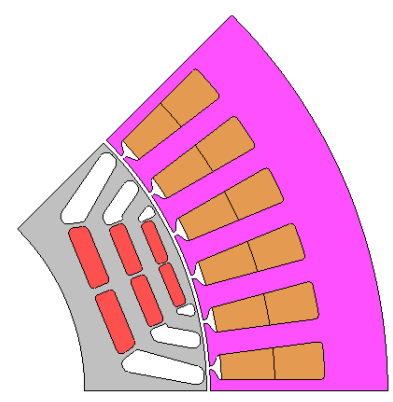

(a)

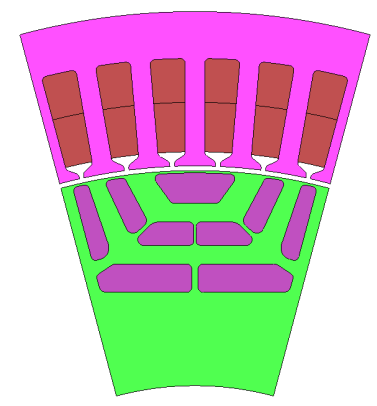

(b)
Fig. 2. Structure of (a) NdFeB machine (b) Ferrite machine

TABLE VI

FEA RESULTS

\begin{tabular}{ccc}
\hline \hline Parameter & NdFeB rotor & Ferrite rotor \\
\hline Torque at rated speed $(\mathrm{Nm})$ & 452.8 & 410 \\
Voltage at rated speed(V) & 433 & 436 \\
Torque at maximum speed $(\mathrm{Nm})$ & 149 & 145 \\
Voltage at maximum speed $(\mathrm{V})$ & 475 & 476 \\
\hline \hline
\end{tabular}

given in Fig. 2. Even though the bore diameter is different, the outer diameter of both machines are nearly the same. This results due to the increased slot depth in $\mathrm{NdFeB}$ machine in order to maintain the current density same as the ferrite machine. In order to achieve the same torque output from both machines, the number of conductors per slot for the $\mathrm{NdFeB}$
TABLE VII

MATERIAL PARAMETER FOR STRESS ANALYSIS

\begin{tabular}{cccc}
\hline \hline Parameter & 35HXT780T & NdFeB & Ferrite \\
\hline Density $\left(\mathrm{kg} / \mathrm{m}^{3}\right)$ & 7600 & 7500 & 5000 \\
Poisson's ratio & 0.3 & 0.3 & 0.29 \\
Young's modulus (GPa) & 210 & 210 & 210 \\
\hline \hline
\end{tabular}

machine is more compared to the ferrite machine. This is due to the reduced stack length and pole number of the $\mathrm{NdFeB}$ based PM-SynRel machine.

The electromagnetic FEA results of both rotors are given in Fig. 1. The flux density plot at rated condition are shown in Fig. 1(a) and 1(d) while Fig. 1(b) and 1(e) gives the flux density plot at maximum speed. The PM flux in NdFeB machine is found to be significant even during maximum field weakening high speed operation. This widely supports the machine in achieving the high speed torque requirement. However, the drawback of this is the induced emf being significantly high during fault condition. The torque and voltage at rated and maximum speed of operation are listed in Table VI. Both machines are found to satisfy the torque requirements. The torque at rated speed is obtained from MTPA operation. This results in the voltage being less that the maximum allowable phase voltage. However, the phase voltage is very close to the maximum allowable voltage in case of operation at maximum speed due to field weakening.

The mechanical performance of both $\mathrm{NdFeB}$ and ferrite 
rotors in the form of Von Mises stress are shown in Fig. 1(c) and 1(f) respectively. The parameters of the rotor materials considered for stress analysis are listed in Table VII. The structural analysis is performed at $16500 \mathrm{rpm}$ considering a safety factor of $10 \%$ on the maximum speed of operation. The maximum stress in $\mathrm{NdFeB}$ and ferrite rotors are found to be $835 \mathrm{MPa}$ and $836 \mathrm{MPa}$ respectively. This is below the yield limit of 35HXT780T.

\section{COMPARISON OF NDFEB AND FERRITE BASED PM-SYNREL}

The NdFeB and ferrite based PM-SynRel machines will be compared based on their electromagnetic and volumetric performance in this section. Various parameters of both machines are listed in Table VIII and its final column holds the relationship between $\mathrm{NdFeB}$ and ferrite machine. The metrics of comparison are chosen as the torque, losses, mass and the machine dimensions.

The outer diameter of the rotor for the $\mathrm{NdFeB}$ machine is less than the ferrite machine. This reduces the peripheral speed of the machine for the same $\mathrm{r} / \mathrm{min}$. The reduction in peripheral speed significantly reduces the mechanical stress in the rotor and makes the design relatively simple. The stack length is $60 \mathrm{~mm}$ more for the ferrite machine. This increase in stack length will reduce the critical speed of the rotor. Critical speed is a very important factor which limits the maximum speed of operation in case of high speed machines. The increase in both rotor diameter and stack length will make the mechanical design of ferrite rotor complex.

The rated and high speed torque of both machines satisfy the requirement. The torque speed characteristics of both ferrite and NdFeB PM-SynRel machines can be visualized from Figs. $3(\mathrm{a})$ and (b) respectively. The rated torque of $\mathrm{NdFeB}$ is nearly $10 \%$ more than the ferrite machine. This high value of torque is obtained from a small machine which higly increases the torque density of the $\mathrm{NdFeB}$ machine. The torque at maximum speed is nearly the same for both the machines. The angle of advance required at maximum speed of operation is $83^{\circ}$ and $81.5^{\circ}$ for $\mathrm{NdFeB}$ and ferrite machine respectively. The field weakening of $\mathrm{NdFeB}$ is quite difficult and it requires more demagnetizing current. This reduces the component of magnet torque more in $\mathrm{NdFeB}$ machine. This explains the reason for nearly similar performance of both machines at the high speed operating region.

The iron loss and copper loss of ferrite machine are higher at the low speed region. This is due to the higher fundamental frequency of operation in ferrite machine and also due to the more volume of the material used. The voltage at the rated speed is well below the maximum limit for both machines. The machines are operated at MTPA and the advance angle of current is selected to achieve the maximum possible torque. However, the copper loss and the iron loss are found to be more for the $\mathrm{NdFeB}$ machine at the high speed operation. This is predominantly due to the field weakening operation. The flux density in the $\mathrm{NdFeB}$ machine is quite high even during the high speed operation compared to the ferrite machine as
TABLE VIII

COMPARISON OF NDFEB AND FERRITE MACHINES

\begin{tabular}{cccc}
\hline \hline Parameter & NdFeB & Ferrite & NdFeB/Ferrite \\
\hline Rotor OD $(\mathrm{mm})$ & 190 & 220 & 0.86 \\
Peripheral Speed $(\mathrm{m} / \mathrm{s})$ & 150 & 175 & 0.85 \\
Stack length $(\mathrm{mm})$ & 160 & 220 & 0.72 \\
$\mathrm{~T}_{\text {avg }}$ at $4500 \mathrm{rpm}(\mathrm{Nm})$ & 452.8 & 410 & 1.1 \\
$\mathrm{~V}_{\text {rms }}$ at $4500 \mathrm{rpm}(\mathrm{Nm})$ & 433 & 436 & 0.99 \\
$\mathrm{~T}_{\text {avg }}$ at $15000 \mathrm{rpm}(\mathrm{Nm})$ & 149 & 145 & 1.02 \\
$\mathrm{~V}_{\text {rms }}$ at $15000 \mathrm{rpm}(\mathrm{Nm})$ & 475 & 476 & 0.997 \\
Iron loss at $4500 \mathrm{rpm}(\mathrm{kW})$ & 0.77 & 1.22 & 0.63 \\
Copper loss at $4500 \mathrm{rpm}(\mathrm{kW})$ & 0.6 & 0.98 & 0.61 \\
Iron loss at $15000 \mathrm{rpm}(\mathrm{kW})$ & 6.6 & 5.4 & 1.2 \\
Copper loss at $15000 \mathrm{rpm}(\mathrm{kW})$ & 3 & 2.36 & 1.27 \\
Total mass $(\mathrm{kg})$ & 58.7 & 80.7 & 0.72 \\
Magnet mass $(\mathrm{kg})$ & 3.7 & 8.8 & 0.42 \\
Copper mass $(\mathrm{kg})$ & 13.7 & 15.6 & 0.87 \\
Iron core mass $(\mathrm{kg})$ & 41.3 & 56.3 & 0.73 \\
Inertia $\left(\mathrm{kgm}{ }^{2}\right)$ & 0.1 & 0.31 & 0.32 \\
Current density $\left(\mathrm{A} / \mathrm{mm}^{2}\right)$ & 12.9 & 13.1 & 0.98 \\
Torque per magnet mass & 122.3 & 46.6 & 2.62 \\
\hline
\end{tabular}

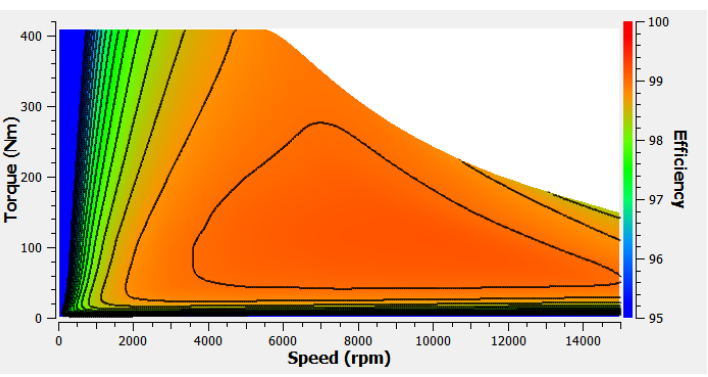

(a)

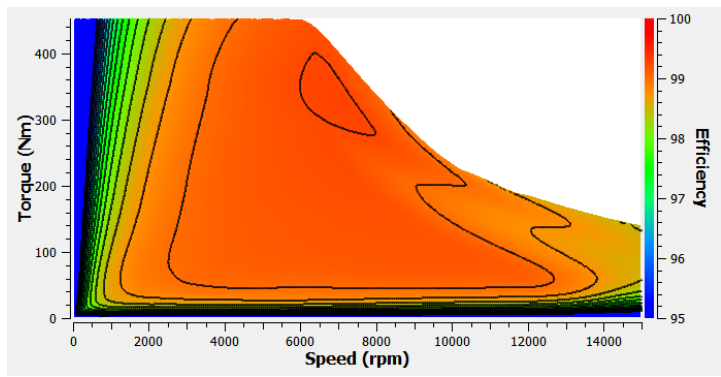

(b)

Fig. 3. Efficiency map of (a) Ferrite and (b) NdFeB PM-SynRel machine

shown in Fig. 1(b) and 1(e) respectively. The iron loss density plots are shown in Fig. 4. The iron loss density of NdFeB machine is found to be higher than that of ferrite machine. This increases the total loss of the $\mathrm{NdFeB}$ machine despite its reduced fundamental frequency and volume. The efficiency map of both ferrite and NdFeB PM-SynRel machines are shown in Figs. 3(a) and (b) respectively. It can be observed that the efficiency at low speed region is more for $\mathrm{NdFeB}$ PM-SynRel machine while its higher for ferrite PM-SynRel machine in high speed region.

The mass of various components are listed in Table VIII. The total mass of $\mathrm{NdFeB}$ machine is $22 \mathrm{kgs}$ less than that of the ferrite machine. This is a significant reduction especially in applications like EVs. Another major factor is the mass of magnets used. $3.7 \mathrm{kgs}$ of $\mathrm{NdFeB}$ is used in contrast to the 8.8 


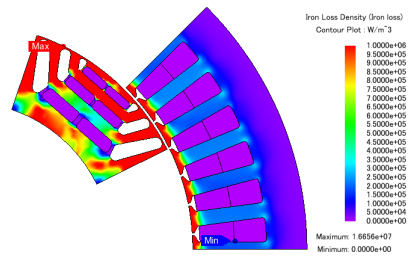

(a)

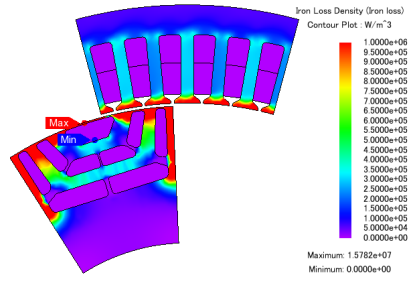

(b)
Fig. 4. Iron loss density for (a) NdFeB machine (b) ferrite machine

kgs of ferrite magnets. Though the ferrite magnets are cheap, building a machine incorporating such high volume of magnet is a design challenge. The mass of copper and also that of lamination is found to reduce in a NdFeB machine. All these aspects ascertain the superior power density and good torque density of $\mathrm{NdFeB}$ machine compared to ferrite machine.

Inertia of the machine influences the maximum acceleration and deceleration possible with the vehicle. EVs in the market are rated based on their time to accelerate from 0 to $100 \mathrm{~km} / \mathrm{hr}$. Inertia is found to rapidly increase with the diameter of the rotor. This results in the ferrite rotor having thrice the inertia compared to the $\mathrm{NdFeB}$ machine. Increase in inertia also makes the response sluggish and reduces the driving comfort.

The NdFeB machine is found to perform better than the ferrite machine in all the aspects other than the high speed losses. The high speed losses can be regulated in the $\mathrm{NdFeB}$ machine by controlling the volume of the PM material. In addition to this, the duration of high speed operation for urban drive cycle is significantly less.

\section{CONCLUSION}

This paper discusses the current trends of electric machines used in EVs. The importance of high power high speed PM-SynRel to reduce the volume of rare earth magnets is highlighted. Based on this, two high power high speed PMSynRel machines with $\mathrm{NdFeB}$ and ferrite rotor are designed for traction application. The performance of both machines are validated using electromagnetic and mechanical FEA.

The NdFeB and ferrite PM-SynRel are compared based on torque, mass, dimension and losses. The significant outcomes of the comparison are listed below:

- The rotor outer diameter, peripheral speed and the stack length are less for a NdFeB machine. This reduces the mechanical stress on the rotor.

- The torque at rated speed is $10 \%$ higher for the $\mathrm{NdFeB}$ machine while their high speed performance is nearly similar.

- The loss in low speed region is more for ferrite machine while the loss in $\mathrm{NdFeB}$ machine is more for the high speed operation. This happens due to high demagnetization current in $\mathrm{NdFeB}$ machine.

- The total mass is reduced by $22 \mathrm{kgs}$ for the $\mathrm{NdFeB}$ machine while the volume of magnet required is one third of the ferrite PM-SynRel.
- Ferrite magnets have always been associated with reduced cost compared to rare earth magnets. However, in this case, the use of Ferrite magnets does not result in cost reduction, as the overall machine volume increases.

- With the advent of high speed processors, the power electronic converter reacts much faster to transients compared to the electric machine. The inertia of the rotor adversely effects the transient response. Inertia of the $\mathrm{NdFeB}$ based PM-SynRel machine is nearly one third of ferrite machine. This enables superior control in case of NdFeB PM-SynRel machines.

The PM-SynRel machine is found to be a suitable alternative for IPM machine in EVs. The rare earth based PM-SynRel will be able to satisfy all the requirements of EVs in terms of government standards and customer demands.

\section{REFERENCES}

[1] "The Roadmap Report Towards 2040: A Guide to Automotive Propulsion Technologies," Advanced Propulsion Centre UK, 2018.

[2] B. Sarlioglu, C. T. Morris, D. Han and S. Li, "Driving Toward Accessibility: A Review of Technological Improvements for Electric Machines, Power Electronics, and Batteries for Electric and Hybrid Vehicles," IEEE Ind. App. Magazine, vol. 23, no. 1, pp. 14-25, Jan.-Feb. 2017.

[3] F. Schlachter, "Has the battery bubble burst," APS News, 2012.

[4] J. F. Gieras, "Permanent magnet motor technology: design and applications," CRC press, 2009.

[5] N. Zhao and N. Schofield, "Field-Weakening Capability of Interior Permanent-Magnet Machines With Salient Pole Shoe Rotors," IEEE Trans. on Magn., vol. 53, no. 11, pp. 1-7, Nov. 2017, Art no. 8112607.

[6] D. Gerada, A. Mebarki, N. L. Brown, C. Gerada, A. Cavagnino and A. Boglietti, "High-Speed Electrical Machines: Technologies, Trends, and Developments," IEEE Trans. on Ind. Electron., vol. 61, no. 6, pp. 2946-2959, June 2014

[7] G Pellegrino, T. M. Jahns, N. Bianchi, W.L. Soong, F. Cupertino, "The rediscovery of synchronous reluctance and ferrite permanent magnet motors: tutorial course notes," Springer, Apr 2016.

[8] S. Morimoto, M. Sanada and Y. Takeda, "Performance of PM-assisted synchronous reluctance motor for high-efficiency and wide constantpower operation," IEEE Trans. on Ind. Appl., vol. 37, no. 5, pp. 1234 1240, Sept.-Oct. 2001.

[9] F. Un-Noor, et al, "A comprehensive study of key electric vehicle (EV) components, technologies, challenges, impacts, and future direction of development," Energies 10.8 (2017): 1217.

[10] M. Ehsani, K. M. Rahman and H. A. Toliyat, "Propulsion system design of electric and hybrid vehicles," IEEE Trans. on Ind. Electron., vol. 44, no. 1, pp. 19-27, Feb. 1997.

[11] T. A. Burress, et al,"Evaluation of the 2010 Toyota Prius hybrid synergy drive system," No. ORNL/TM-2010/253, Oak Ridge National Lab(ORNL), Oak Ridge, TN (United States), Power Electronics and Electric Machinery Research Facility, 2011.

[12] X. Ge, Z. Q. Zhu, J. B. Li and J. T. Chen, "A spoke-type IPM machine with novel alternate airspace barriers and reduction of unipolar leakage flux by step-staggered rotor," IEMDC, ID, 2015, pp. 53-59.

[13] T. Noguchi,Y. Takata, Y. Yamashita,Y. Komatsu and S Ibaraki, "220000$\mathrm{r} / \mathrm{min}, 2 \mathrm{~kW}$ PM Motor Drive for Turbocharger," IEEJ Trans. on Ind. Appl., 125. 854-861.

[14] J. Merwerth, "The hybrid-synchronous machine of the new BMW i3 \& i8 challenges with electric traction drives for vehicles, BMW Group," Workshop University Lund 2014.

[15] S. Jurkovic, et al, "Next generation voltec electric machines; design and optimization for performance and rare-earth mitigation," SAE International Journal of Alternative Powertrains 4.2, (2015): 336-342. 